Wei-Lung Tseng

Ming-Feng Huang

Yu-Fen Huang

Huan-Tsung Chang

Department of Chemistry, National Taiwan University, Taipei, Taiwan

\section{Nanoparticle-filled capillary electrophoresis for the separation of long DNA molecules in the presence of hydrodynamic and electrokinetic forces}

\begin{abstract}
We report the analysis of long DNA molecules by nanoparticle-filled capillary electrophoresis (NFCE) under the influences of hydrodynamic and electrokinetic forces. The gold nanoparticle (GNP)/polymer composites (GNPPs) prepared from GNPs and poly(ethylene oxide) were filled in a capillary to act as separation matrices for DNA separation. The separations of $\lambda$-DNA $(0.12-23.1 \mathrm{kbp})$ and high-molecular-weight DNA markers $(8.27-48.5 \mathrm{kbp})$ by NFCE, under an electric field of $-140 \mathrm{~V} / \mathrm{cm}$ and a hydrodynamic flow velocity of $554 \mu \mathrm{m} / \mathrm{s}$, were accomplished within $5 \mathrm{~min}$. To further investigate the separation mechanism, the migration of $\lambda$-DNA was monitored in real time using a charge-coupled device (CCD) imaging system. The GNPPs provide greater retardation than do conventional polymer media when they are encountered during the electrophoretic process. The presence of interactions between the GNPPs and the DNA molecules is further supported by the fluorescence quenching of prelabeled $\lambda$-DNA, which occurs through an energy transfer mechanism. Based on the results presented in this study, we suggest that the electric field, hydrodynamic flow, and GNPP concentration are the three main determinants of DNA separation in NFCE.
\end{abstract}

Keywords: Capillary electrophoresis / DNA separation / Gold nanoparticles / Poly(ethylene oxide)

DOI 10.1002/elps.200410433

\section{Introduction}

Pulsed-field gel electrophoresis (PFGE) is currently the method of choice for the analysis of long DNA molecules, but it is very time-consuming and difficult to integrate [1-4]. To overcome these shortages, alternative methods, such as capillary pulsed gel electrophoresis, have been developed [5-9]. Like PFGE, however, capillary pulsed gel electrophoresis has some shortages: the resolution of the separation of long DNA molecules decreases as their molecular mass increases, reproducibility can be problematic, and the system's requirements are rather complicated. Very recently, the use of chipbased nanostructures [10-16] and the filling of nanoparticle media into microchannels [17-23] have been demonstrated to be applicable to the separation of long DNA molecules. Following the report of the first etched microlithographic array of posts [10], recent research has

Correspondence: Dr. Huan-Tsung Chang, Department of Chemistry, National Taiwan University, No. 1, Sec. 4, Roosevelt Road, Taipei 106, Taiwan

E-mail: changht@ntu.edu.tw

Fax: + 886-2-2362-1963

Abbreviations: $\mathrm{EtBr}$, ethidium bromide; GNP, gold nanoparticle; GNPP, GNP/PEO composite; HMW, high-molecular-weight; NFCE, nanoparticle-filled capillary electrophoresis; PEO, poly(ethylene oxide) produced separation devices based on asymmetric Brownian ratchets [11, 12], entropic traps [13, 14], and nanopatterned surfaces [15]. The operating principles applied in these devices rely on the effects that the size, shape, and/or surface properties of the nanostructures have on the mobility of the DNA chains. For example, a nanopillar-based separation system has been employed to separate long DNA molecules in which the spacing between the pillars was smaller than the normal geometric size (e.g., the radius of gyration) of the DNA analytes [16]. When the DNA molecules intruded into the nanopillar channel, they migrated at different velocities according to their molecular weights, which indicates that the nanopillars produce a molecular sieving effect and function as a DNA sieving matrix. The fabrication of these devices however requires sophisticated techniques and is costly. A promising new alternative is the use of self-assembled magnetic particles (having diameters on the order of a few micrometers) for the microfluidic separation of large DNA fragments under a homogeneous magnetic field $(>10 \mathrm{mT})$ [17]. A medium composed of self-assembled posts of a ferrofluid having interpost spacings of $5 \mu \mathrm{m}$ provides high resolving power for the separation, within $10-15 \mathrm{~min}$, of $48.5 \mathrm{kbp}$ $\lambda$-DNA and associated fragments ( 15 and $33.5 \mathrm{kbp}$ ). This new device, along with the nanostructures mentioned above, shares, however, the same shortages; it is difficult 
to predict the nanostructure dependence of the DNA mobility, which characterizes the degree of separation and dispersion of DNA molecules.

Recently, we introduced two new CE approaches for the analysis of long DNA molecules [20-22]. Using poly(ethylene oxide) (PEO) solutions containing gold nanoparticles (GNPs), we demonstrated the separation and analysis of $5 \mathrm{kbp}$ DNA ladders $(5-40 \mathrm{kbp})$ under a constant electric field $(25 \mathrm{~V} / \mathrm{cm})$; the reproducibility was good, but the separation was slow (within $27 \mathrm{~min}$ ) [20]. To shorten the analysis time, we developed nanoparticle-filled capillary electrophoresis (NFCE). In NFCE, the capillary is filled with GNP/PEO composites (GNPPs) [21]. The separation is based on the interactions between the GNPPs and DNA molecules. Using high-molecularweight $(\mathrm{HMW})$ GNPPs $\left(>2.0 \times 10^{8} \mathrm{~g} /\right.$ particle) that have a very small electrophoretic mobility $\left(7.01 \times 10^{-5} \mathrm{~cm}^{2} \mathrm{~N} \cdot \mathrm{s}\right)$, DNA migration is retarded by interactions (collisions) with the GNPPs [24, 25]. Additionally, core-shell-type globular nanoparticles have been applied in microchip CE to the separation of DNA fragments having sizes ranging from 1 to $15 \mathrm{kbp}$ [23]. The separation time can be shortened to $100 \mathrm{~s}$ when pressure is applied, while the resolution is retained as a result of the stacking effect of the nanoparticles on the DNA fragments.

The goals of this work were to prepare GNPPs in a simple and rapid manner, to further improve the resolution of the separation of the long DNA molecules by applying electrical and hydrodynamic forces simultaneously, and to gain insight into the separation mechanism.

\section{Materials and methods}

\subsection{Chemicals}

Sodium tetrachloroaurate(III) dehydrate was obtained from Sigma (St. Louis, MO, USA). Trisodium citrate was obtained from Riedel-de Haën (Seelze, Germany). PEO $\left(M_{\mathrm{w}}: 8 \times 10^{6}\right)$, PEO $\left(M_{\mathrm{w}}: 2 \times 10^{6}\right)$, and PVP $\left(M_{\mathrm{w}}\right.$ : $1.3 \times 10^{6}$ ) were purchased from Aldrich (Milwaukee, WI, USA), respectively. Glycine was purchased from ICN Biomedicals (Aurora, OH, USA). Ethidium bromide (EtBr) was obtained from Pharmacia Biotech (Uppsala, Sweden). It should be noted that $\mathrm{EtBr}$ is a highly carcinogenic compound and must be handled after wearing gloves. $\lambda$-DNA was purchased from Amersham Pharmacia Biotech (Piscataway, NJ, USA) and the HMW DNA marker was purchased from Life Technologies (Rockville, MD, USA). $\lambda$-DNA (48 502 bp) was obtained from Fluka (Buchs, Switzerland). The glycine-citrate buffer consisted of glycine $\left(\mathrm{p} K_{\mathrm{a} 1}=2.35\right.$ and $\left.\mathrm{p} K_{\mathrm{a} 2}=9.778\right)$ and trisodium citrate $\left(\mathrm{p} K_{\mathrm{a} 1}=3.128, \mathrm{p} K_{\mathrm{a} 2}=4.761\right.$, and $\left.\mathrm{p} K_{\mathrm{a} 3}=6.396\right)$ was used to adjust the $\mathrm{pH}$. In this paper, the molarity of the glycinecitrate buffers refers to that of glycine.

\subsection{CE}

We have described our home-built CE setup, equipped with laser-induced fluorescence detection, in a previous paper [21]. Briefly, a high-voltage power supply (Gamma High Voltage Research, Ormond Beach, FL, USA) was used to drive electrophoresis and $4 \mathrm{~mW}$ of 543.5-nm laser light from an He-Ne laser (model 1675; Uniphase, Manteca, CA, USA) was used for excitation. The fluorescence light was collected with a $10 \times$ objective (numeric aperture 0.25). One RG 610 cutoff filter (Edmund Industrial Optics, Barrington, NJ, USA) was used to block scattered light before the emitted light reached the phototube (R928; Hamamatsu Photonics K. K., Shizuoka-Ken, Japan). The fluorescence signal was transferred directly through a $10-\mathrm{k} \Omega$ resistor to a 24-bit A/D interface operated at $10 \mathrm{~Hz}$ (Borwin, JMBS Developments, Le Fontanil, France) and stored in a PC. The 40-cm capillaries (Polymicro Technologies, Phoenix, AZ, USA), which had $75 \mu \mathrm{m}$ id and $365 \mu \mathrm{m}$ od, were coated dynamically overnight using 5.0\% PVP prior to use in DNA separations.

\subsection{Fluorescence imaging}

The optical setup we used to observe the migration of $\lambda$-DNA in the capillary was similar to that reported by Preisler and Yeung [26]. A CCD camera (Andor Technology, Belfast, Northern Ireland) equipped with a 25-mm AVENIR camera lens was used for image capture. The light at $532 \mathrm{~nm}$ emitted from a $10-\mathrm{mW}$ solid-state laser was focused by a convex lens and expanded horizontally to $5 \mathrm{~cm}$ upon the detection window by the use of two cylindrical lenses. The polyimide coating of the capillary was removed from a 3.6-cm segment to impart the capillary with optical transparency. The CCD camera exposure frequency was $5.5 \mathrm{~Hz}$, and the exposure time was $100 \mathrm{~ms}$ for each frame. Each frame consists of 510 (horizontal) $\times 54$ (vertical) pixels. We calculated the velocity of $\lambda$-DNA between the 505th and 25th pixels, which corresponded to the $3.4 \mathrm{~cm}$ capillary length. One RG-590 nm cutoff filter (Edmund Industrial Optics) was used to eliminate scattered light before the emitted light entered into the CCD camera.

\subsection{Synthesis of GNPs and GNPPs}

The 32-nm GNPs were prepared according to the reported methods [27]. Briefly, $0.01 \% \mathrm{AuCl}_{4}{ }^{-}$solution $(50 \mathrm{~mL})$ was heated under reflux and then $1 \%$ trisodium 
citrate $(0.5 \mathrm{~mL})$ was added. The mixture was heated for a further $8 \mathrm{~min}$, during which time the solution changed its color from pale-yellow to purple, indicating the formation of the 32-nm GNPs. The solution was cooled to room temperature and then its UV-Vis absorption spectrum was recorded, which displayed the surface plasmon resonance band at $528 \mathrm{~nm}$. Transmission electron microscopy (TEM) images (not shown) further confirmed that the size of the GNPs is $32 \mathrm{~nm} \pm 9 \%$ ) [27]. The preparation of the GNPPs was conducted by mixing the GNPs directly with PEO. The PEO(2 MDa) and $\mathrm{PEO}(8 \mathrm{MDa})$ solutions, which have molecular weights $\left(M_{\mathrm{w}}\right)$ of $8 \times 10^{6}$ and $2 \times 10^{6}$ (Aldrich), were dissolved in $10 \mathrm{~mm}$ glycine-citrate solution ( $\mathrm{pH} 7.0)$. Aliquots of $0.1 \%$ PEO solutions $(0.1-20 \mu \mathrm{L})$ were added separately to different concentrations of the GNPs solutions $(1-10 \times)$ such that the final volume of the mixture was $1 \mathrm{~mL}$ and the final concentrations of PEO ranged from 0.00005 to $0.003 \%$. The solutions were equilibrated at ambient temperature and pressure overnight and then mixed with a suitable concentration of EtBr.

\subsection{NFCE}

Before conducting separations, the dynamically coated capillary was flushed with deionized water to remove PEO and then filled with the GNPPs by applying a low pressure (syringe pushing). DNA samples were hydrodynamically injected at the cathode end into the coated capillary at a $15-\mathrm{cm}$ height for $15 \mathrm{~s}$ when fluorescence images were taken and at a $20-\mathrm{cm}$ height for $5 \mathrm{~s}$ when conducting CE separations. The separations were conducted at electric fields ranging from -60 to $-260 \mathrm{~V} / \mathrm{cm}$. Hydrodynamic flow was applied by changing the cathodic height of the buffer reservoir. After each run, the solution of GNPPs was flushed out using low pressure.

\section{Results and discussion}

\subsection{Impacts of hydrodynamic and electrokinetic forces on the migration of $\lambda$-DNA}

To understand the roles that the GNPPs and the driving forces have on DNA separation, we monitored the migration of $\lambda$-DNA in PEO solution and in the presence of GNPP(PEO2) and GNPP(PEO8) under the separate influences of an electric field (electrokinetic force) and pressure (hydrodynamic force). In this study, GNPP(PEO2) and GNPP(PEO8) denote GNP/PEO $\left(M_{\mathrm{w}}: 2 \times 10^{6}\right)$ and GNP/ PEO $\left(M_{\mathrm{w}}: 8 \times 10^{6}\right)$ composites, respectively. Figure $1 \mathrm{~A}$ and $B$ presents $C C D$ images of the initial progress of $\lambda$-DNA in the capillary (traveling region is within $3.6 \mathrm{~cm}$ of the injection end). Within $40 \mathrm{~s}$, the migration velocity of $\lambda$-DNA in the PEO solution was greater than it was in either of the GNPP matrices under an electric field of $-140 \mathrm{~V} / \mathrm{cm}$ (Fig. $1 \mathrm{~A})$, mainly because of the differential retardation effect of the separation matrices. Relative to the effect of the PEO molecules $\left(8 \times 10^{6} \mathrm{~g} / \mathrm{mol}\right)$, the GNPPs $\left(2 \times 10^{8} \mathrm{~g} / \mathrm{mol}\right.$ for the 32-nm GNP) retard the DNA molecules to a greater extent once they are encountered during collision. In addition to the mass effect, the interactions between the PEO molecules adsorbed on the GNPs and the DNA strands lead to the small electrophoretic mobility in the GNPP(PEO2)-filled capillary. It has been reported that when the size of the polymer molecule is large relative to
A

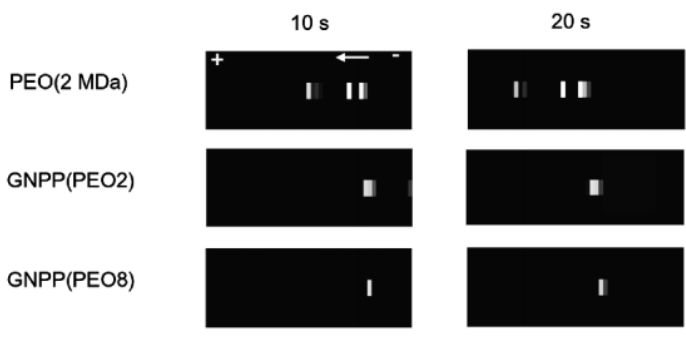

B
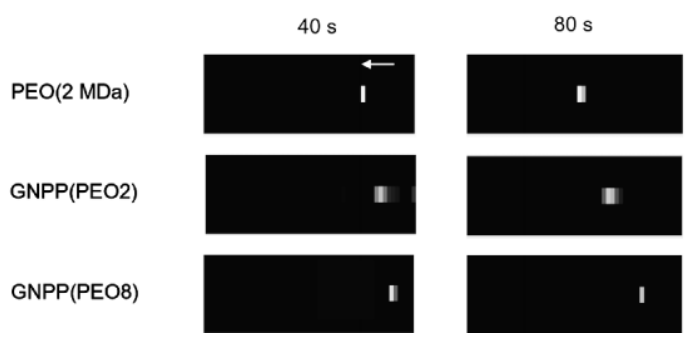

$40 \mathrm{~s}$

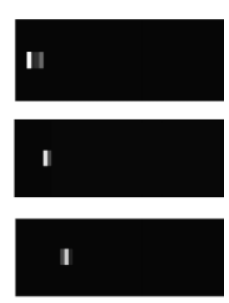

$160 \mathrm{~s}$

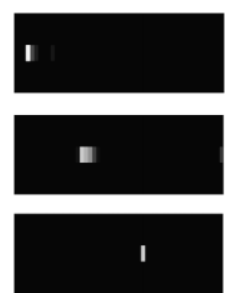

Figure 1. Electrophoretic behavior of $\lambda$-DNA in GNPPs and conventional polymer media. CCD images display the electrophoretic movement of $\lambda$-DNA $(100.0 \mu \mathrm{g} / \mathrm{mL})$ at different times under an electric field of $-140 \mathrm{~V} / \mathrm{cm}(\mathrm{A})$ in the presence and (B) absence of a hydrodynamic flow $(554 \mu \mathrm{m} / \mathrm{s})$. Images of the initial progress of $\lambda$-DNA were recorded in the region $3.6 \mathrm{~cm}$ from the injection end. Three separation media$0.002 \%$ PEO(2 MDa), $3 \times$ GNPP(PEO2), and $5 \times$ GNPP(PEO8) - were prepared in $10 \mathrm{~mm}$ glycine-citrate solution ( $\mathrm{pH} 7.0$ ) containing $0.5 \mu \mathrm{g} /$ $\mathrm{mL}$ EtBr. Total length and effective length are 40 and $7 \mathrm{~cm}$, respectively. DNA samples were injected hydrodynamically at $15 \mathrm{~cm}$ for $15 \mathrm{~s}$. 
that of the particle, a few loops or tails protrude into the solution [28, 29]. Similarly, the retardation of the DNA molecules caused by the GNPPs is greater in the presence of hydrodynamic flow because of the small degree of diffusion of the GNPPs and their interaction with the capillary wall (Fig. 1B). When comparing the electropherogram patterns (Fig. 2), at least three peaks corresponding to $\lambda$-DNA molecules were resolved when the PEO solution was used, but only one peak is observed in the case of the GNPP-filled capillaries [21]. The high electric field not only breaks up the secondary and tertiary structures of the nucleic acids but also induces the occurrence of aggregation [30-34], which leads to changes in the electropherogram patterns. We note that only one broadband for each initial sample plug was observed when we monitored the injection of the DNA intercalated with $0.5 \mu \mathrm{g} / \mathrm{mL}$ EtBr. Further evidence that $\lambda$-DNA cleaves or aggregates in PEO solution under the influence of the high electric field is provided by the fact that there we observed only one single band in the absence of electric field (Fig. 1B). We suggest that the presence of the GNPPs can minimize the degree of cleavage and aggregation of $\lambda$-DNA under a high electric field, which results in greater separation efficiency. The effects that the GNPPs have on the stability of the DNA molecules are likely to be due to the interactions between these species, which lead to less access for cleavage and extension of DNA molecules to minimize hydrophobic patches. By using digested $\lambda$-DNA $(0.12-23.1 \mathrm{kbp})$, we found that the optimum concentrations for separation were $3 \times$ GNPP(PEO2) and $5 \times$ GNPP(PEO8), respectively; we define the concentration of the as-prepared GNPs to be $1 \times$ (the concentration is $\sim 1.6 \times 10^{11}$ particles $/ \mathrm{mL}=0.27 \mathrm{~nm}$ ).

The role that the hydrodynamic flow plays in determining the degree of DNA separation was investigated by Yeung et al. [35-37], who demonstrated that a mixture of $\lambda$-DNA

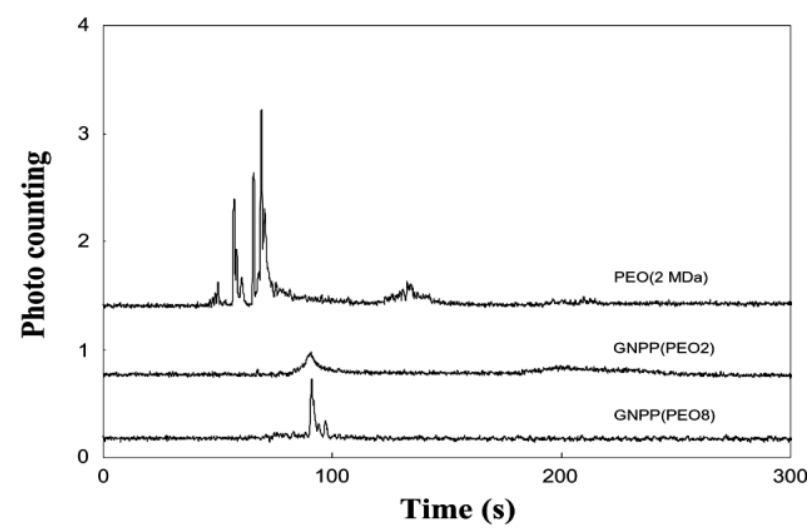

Figure 2. Electropherograms of $\lambda$-DNA in GNPPs and conventional polymer media. Data shown in Figs. $1 A-C$ were transferred to electropherograms $A, B$, and $C$, respectively, by using Andor software. and $\Phi \times 174$ RF DNA digests could be separated when applying four cycles of hydrodynamic flow (for $1 \mathrm{~min}$ each) between applications of the electric field. These authors found that when an electric field is applied to induce electrophoretic motion in the same direction as the hydrodynamic flow, DNA molecules become focused and move toward the center of the capillary, which leads to a decrease in both band broadening and cleavage. As a result, a greater resolution of long DNA molecules is achieved. On the basis of these authors' results and our observations (Fig. 1), we believe that the separation of long DNA molecules should benefit from the application of hydrodynamic flow in the same direction as that of the DNA migration under an applied electric field. The hydrodynamic flow was generated by setting the cathodic reservoir to a value higher than the anodic one, and the flow velocities for hydrodynamic flow were 399-899 $\mu \mathrm{m} / \mathrm{s}$ when the height differences of $4.0-8.5 \mathrm{~cm}$ were adjusted. At constant GNPP concentrations, a hydrodynamic flow of $554 \mu \mathrm{m} / \mathrm{s}$ is suitable in terms of resolution and speed. The contribution that the hydrodynamic flow provides to the rate of travel of the DNA molecules is greater than $12 \%$ under an electric field of $-140 \mathrm{~V} / \mathrm{cm}$ (Table 1 ). The decreasing order of the hydrodynamic flow velocities is attributable mainly to the increased viscosity and decreased diffusion coefficients of the separation matrices. Table 1 also presents the calculated velocities $\left(V_{1}\right)$ for $\lambda$-DNA, which are $8.60 \times 10^{-2}, 7.41 \times 10^{-2}$, and $6.90 \times 10^{-2} \mathrm{~cm} / \mathrm{s}$ in $0.002 \% \operatorname{PEO}(2 \mathrm{MDa}), 3 \times$ GNPP(PEO2), and $5 \times$ GNPP(PEO8), respectively.

\subsection{Separation of $\lambda$-DNA and HMW DNA}

Using $3 \times$ GNPPs, the digested $\lambda$-DNA $(0.12-23.1 \mathrm{kbp})$ and fragments of HMW DNA (8.2-48.5 kbp) were resolved well, apart from the $48.5 / 38.4 \mathrm{kbp}$ pair, within 5 min under an electric field of $-140 \mathrm{~V} / \mathrm{cm}$ and a hydrodynamic flow velocity of $554 \mu \mathrm{m} / \mathrm{s}$ (Figs. 3A and B). The RSD of the migration times for $\lambda$-DNA fragments in triplicate runs are less than $0.8 \%$. The number of theoretical plates of the HMW DNA fragments ranges from $3.5 \times 10^{5}$ to $2.2 \times 10^{6}$. Because a long DNA fragment has a larger radius of gyration and stretched length (e.g., 48.5-kbp DNA has gyration radius and fully stretched length of $520 \mathrm{~nm}$ and $21 \mu \mathrm{m}$, respectively) [38], it has a greater probability of interacting simultaneously with more than one GNPP and, hence, its dragging force is stronger relative to that of a short fragment. Our hypothesis is supported by the fact that the values of the electrophoretic mobility of $\lambda$-DNA in $5 \times$ GNPP(PEO8) at $-60,-140$, and $-260 \mathrm{~V} / \mathrm{cm}$ are $6.70 \times 10^{-4}, 4.93 \times 10^{-4}$, and $3.48 \times 10^{-4} \mathrm{~cm}^{2} \mathrm{~N} \cdot \mathrm{s}$, respectively. Under a high elec- 
Table 1. Effect of the hydrodynamic flow on the mobility of $\lambda$-DNA under an electric field of $-140 \mathrm{~V} / \mathrm{cm}$

\begin{tabular}{|c|c|c|c|c|c|c|}
\hline \multirow[b]{2}{*}{ Separation matrix } & \multicolumn{2}{|c|}{$\begin{array}{l}\text { Electric field + } \\
\text { hydrodynamic flowa) }\end{array}$} & \multicolumn{2}{|c|}{ Hydrodynamic flow } & \multirow{2}{*}{$\begin{array}{l}\text { Ratio } \\
\overline{\left(V_{2} / V_{1}\right) \times 100 \%}\end{array}$} & \multirow{2}{*}{$\begin{array}{l}\left.\text { Mobility }^{\mathrm{b}}\right) \\
\mu_{\mathrm{ep}} \\
\left(\times 10^{-4} \mathrm{~cm}^{2} \mathrm{~N} \times \mathrm{s}\right)\end{array}$} \\
\hline & $\begin{array}{l}V_{1} \\
\left(\times 10^{-2} \mathrm{~cm} / \mathrm{s}\right)^{\mathrm{a})}\end{array}$ & $\begin{array}{l}\mathrm{RSD} \\
(n=3)\end{array}$ & $\begin{array}{l}V_{2} \\
\left(\times 10^{-2} \mathrm{~cm} / \mathrm{s}\right)\end{array}$ & $\begin{array}{l}\mathrm{RSD} \\
(n=3)\end{array}$ & & \\
\hline PEO(2 MDa) & 8.60 & $2.9 \%$ & 2.04 & $1.0 \%$ & 25.3 & 4.68 \\
\hline GNPP(PEO2) & 7.41 & $1.9 \%$ & 1.50 & $0.8 \%$ & 20.2 & 4.22 \\
\hline GNPP(PEO8) & 6.90 & $3.2 \%$ & 0.84 & $0.9 \%$ & 12.1 & 4.32 \\
\hline
\end{tabular}

a) Velocity of $\lambda$-DNA was calculated between the 505th and 25th pixel, which is a distance that corresponded to the $3.4 \mathrm{~cm}$ capillary length.

b) Electrophoretic mobility was calculated according to the expression $\mu_{\mathrm{ep}}=\left(V_{1}-V_{2}\right) / E$, where $E$ is the strength of the electric field.

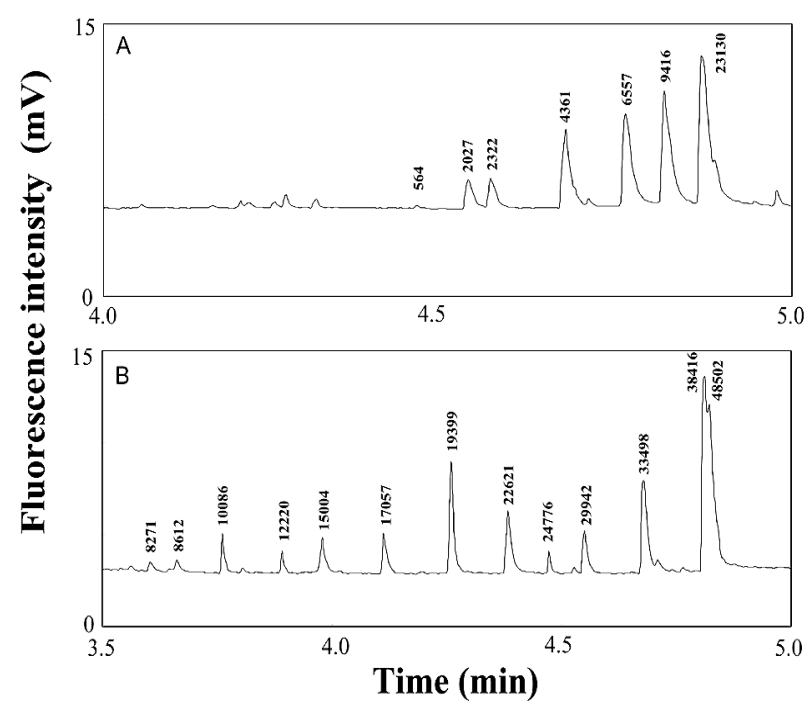

Figure 3. Separations of long DNA fragments in the presence of GNPPs under the influence of electrokinetic and hydrodynamic forces. (A) $\lambda$-DNA fragments $(10 \mu \mathrm{g} /$ $\mathrm{mL})$ in $3 \times$ GNPP(PEO2). (B) HMW DNA fragments $(10 \mu \mathrm{g} /$ $\mathrm{mL}$ ) in $3 \times$ GNPP(PEO2), containing $0.5 \mathrm{~mm} \mathrm{NaCl}$. Number of base pairs of the corresponding DNA fragments is indicated. Fused-silica capillary: $365 \mu \mathrm{m}$ od, $75 \mu \mathrm{m}$ id, $40 \mathrm{~cm}$ total length, and $30 \mathrm{~cm}$ effective length. Separation conditions: pressure injection at $20 \mathrm{~cm}$ for $5 \mathrm{~s}$, separation at $-140 \mathrm{~V} / \mathrm{cm}$, the velocity of hydrodynamic flow is $554 \mu \mathrm{m} / \mathrm{s}$.

tric field, DNA molecules extend to a greater degree, and thus they experience stronger interactions with the GNPPs [39]. When compared with the results of our previous study [21], this new technique has the advantages of greater resolution, rapid separation, excellent reproducibility, ease of preparation, and fewer undesired peaks arising from aggregation, cleavage, and spikes due to scattering.

\subsection{Interactions between DNA and GNPPs}

To further investigate the nature of the collisions between the DNA molecules and GNPPs, we monitored the fluorescence of EtBr-intercalated DNA in $0.002 \%$ PEO(2 MDa), $5 \times$ GNPP(PEO8), and $3 \times$ GNPPs(PEO2), using an imaging system. In our previous study, we found that the fluorescence of EtBr-intercalated DNA is quenched by the GNPPs as a result of energy transfer [21]. To monitor the fluorescence, an EtBr-intercalated $\lambda$-DNA plug was injected hydrodynamically into the capillary from the cathodic end and then this sample plug was pushed close to the observation window. After applying the voltage, the fluorescence intensity of EtBr-intercalated $\lambda$-DNA remained almost constant when $0.002 \% \mathrm{PEO}(2 \mathrm{MDa})$ was used, but the intensity when using GNPPs decreased dramatically (Figs. 4A-C). These results support the notion that interactions occur between the DNA molecules and the GNPPs. Figure 5 provides further evidence that the fluorescence quenching of $\lambda$-DNA resulting from the presence of the GNPPs is small in the absence of the electric field (only hydrodynamic flow exists), mainly because of lower frequency of collisions that arise when $\lambda$-DNA molecules exist in their more compact structures. Again, we note that DNA molecules stretch to a greater extent in high electric fields, which leads to a greater number of their interactions with the GNPPs. Our observed fluorescence quenching supports the notion that the DNA molecules interact with the GNPPs during the course of their separation, which determines the selectivity of separation.

\section{Concluding remarks}

We have demonstrated that the separation of long DNA fragments, with sizes ranging from 8.2 to $48.5 \mathrm{kbp}$, occurs using NFCE, which has the advantages of high efficiency, 
A

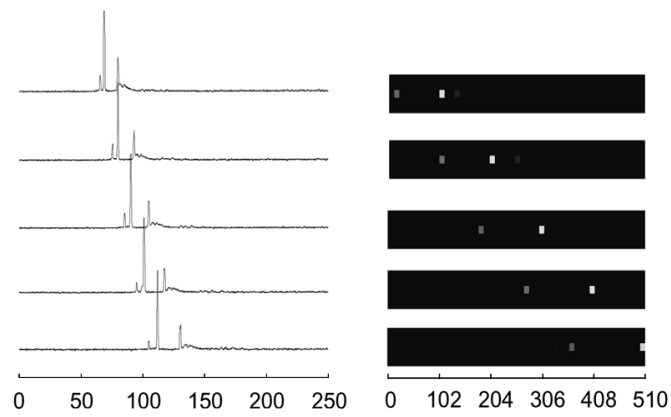

B

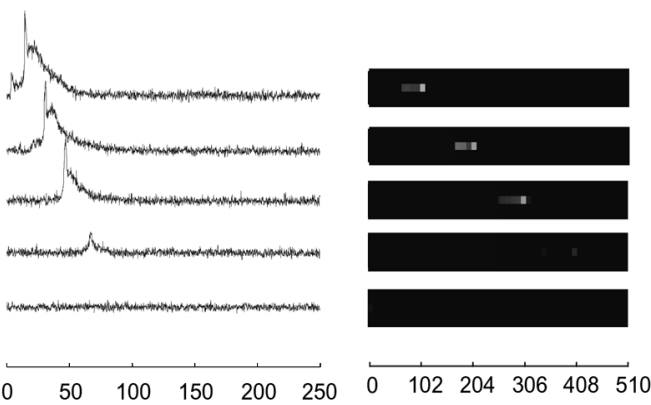

C
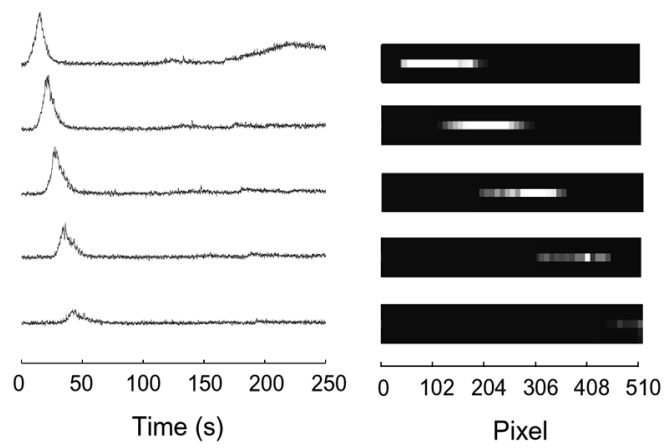

Figure 4. Observations of the fluorescence intensity of $\lambda$-DNA during the electrophoresis process in the different matrices. (A) PEO(2 MDa). (B) GNPP(PEO8) solution containing $5 \times$ GNPs. (C) GNPP(PEO2) solution containing $3 \times$ GNPs. A $50 \mu \mathrm{g} / \mathrm{mL}$ sample of $\lambda$-DNA was prelabeled with $50 \mu \mathrm{g} / \mathrm{mL} \mathrm{EtBr}$. All other conditions are the same as those described in Fig. 1.

high speed, and reproducibility. The interactions between the DNA molecules and GNPPs and hydrodynamic flow have great impacts on the resolution of the process. Our results suggest that the separation efficiency and speed for different DNA samples can be optimized further by using differently sized and shaped GNPPs, or other nanoparticles, and/or by adjusting the velocity of the hydrodynamic flow. When compared with the use of chipbased nanostructures for separating long DNA molecules, NFCE is a simple process that is accessible to most laboratories. The use of polymer-absorbed nanoparticles is fully competitive with-and, in many cases, superior to-the methods employed conventionally for the

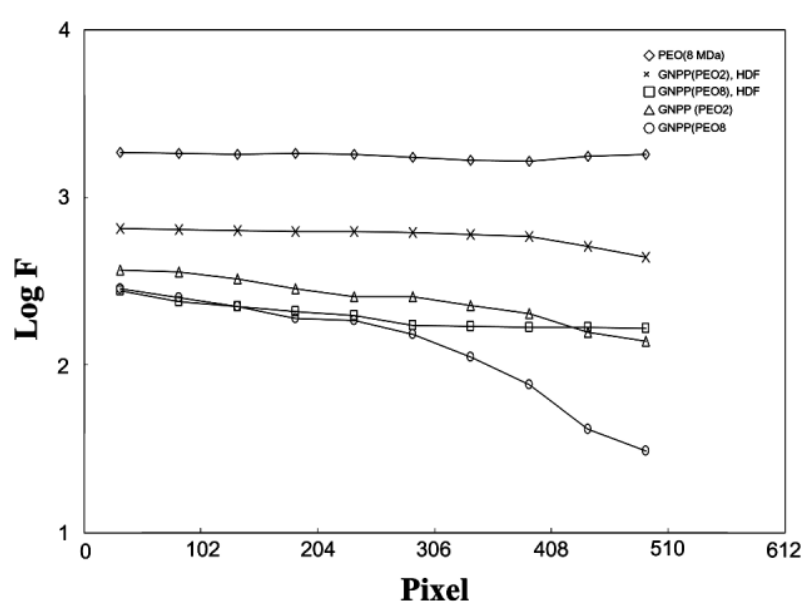

Figure 5. Plots of log $F$ (fluorescence intensity) versus CCD pixels obtained under the various running conditions. * denotes that only hydrodynamic flow was applied. All other conditions are the same as those described in Fig. 4.

separation of long DNA fragments, and this new method has great potential for other applications, such as protein separation.

This study was supported by the National Science Council of Taiwan under contract Nos. NSC 93-2113-M-002-034 and NSC 93-2113-M-002-035. W.-L. T. is grateful to the National Science Council for his postdoctoral fellowship in the Department of Chemistry, National Taiwan University under contract no. NSC 92-2811-M-002-079.

Received December 26, 2004

\section{References}

[1] Lalande, M., Noolandi, J., Turmel, C., Rousseau, J., Slater, G. W., Proc. Natl. Acad. Sci. USA 1987, 84, 8011-8015.

[2] Lalande, M., Noolandi, J., Rousseau, J., Turmel, C., Slater, G. W., Nucleic Acids Res. 1988, 16, 5427-5437.

[3] Turmel, C., Brassard, E., Slater, G. W., Noolandi, J., Nucleic Acids Res. 1990, 18, 569-575.

[4] Maule, J., Mol. Biotech. 1998, 9, 107-126.

[5] Morris, M. D., Schwinefus, J. J., de Carmejane, O., Methods Mol. Biol. 2001, 162, 307-321.

[6] Sudor, J., Novotny, M. V., Anal. Chem. 1994, 66, 2446-2450.

[7] Kim, Y., Morris, M. D., Anal. Chem. 1995, 67, 784-786.

[8] Geoun, M. B., Choi, K. S., Lee, Y. -I., Kim, Y., Microchem. J. 2002, 72, 305-313.

[9] Sudor, J., Novotny, M. V., Nucleic Acids Res. 1995, 23, 2538-2543.

[10] Volkmuth, W. D., Austin, R. H., Nature 1992, 358, 600-602.

[11] Chou, C. F., Bakajin, O., Turner, S. W. P., Duke, T., Chan, S. S., Cox, E. C., Craighead, H. C., Darnton, N., Han, J., Austin, R. H., Proc. Natl. Acad. Sci. USA 1999, 96, 13762-13765. 
[12] Huang, L. R., Tegenfeldt, J. O., Kraeft, J. J., Sturm, J. C., Austin, R. H., Cox, E. C., Nat. Biotech. 2002, 20, 1048-1051.

[13] Han, J., Craighead, H. G., Science 2000, 288, 1026-1029.

[14] Han, J., Craighead, H. G., Anal. Chem. 2002, 74, 394-401.

[15] Seo, Y.-S., Luo, H., Samuilov, V. A., Rafailovich, M. H., Sokolov, J., Gersappe, D., Chu, B., Nano Lett. 2004, 4, 659664.

[16] Kaji, N., Tezuka, Y., Takamura, Y., Ueda, M., Nishimoto, T., Nakanishi, H., Horiike, Y., Baba, Y., Anal. Chem. 2004, 76, 15-22.

[17] Doyle, P. S., Bibette, J., Bancaud, A., Viovy, J.-L., Science 2002, 295, 2237

[18] Mayer, P., Bibette, J., Viovy, J.-L., Mater. Res. Soc. Symp. Proc. 1997, 463, 57-66.

[19] Liang, D., Song, L., Chen, Z., Chu, B., Electrophoresis 2001, 22, 1997-2003.

[20] Chiou, S.-C., Huang, M.-F., Chang, H.-T., Electrophoresis 2004, 25, 2186-2192.

[21] Huang, M.-F., Kuo, Y.-C., Huang, C.-C., Chang, H.-T., Anal. Chem. 2004, 76, 192-196.

[22] Huang, M.-F., Huang, C.-C., Chang, H.-T., Electrophoresis 2003, 24, 2896-2902.

[23] Tabuchi, M., Ueda, M., Kaji, N., Yamasaki, Y., Nagasaki, Y., Yoshikawa, K., Kataoka, K., Baba, Y., Nat. Biotechnol. 2004, 22, 337-340.

[24] Schwinefus, J. J., Hammond, R. W., Oana, H., Wang, S.-C., De Carmejane, O., Bonadio, J., Morris, M. D., Macromolecules 1999, 32, 4625-4630.
[25] Sunada, W. M., Blanch, H. W., Biotechnol. Prog. 1998, 14, 766-772.

[26] Preisler, J., Yeung, E. S., Anal. Chem. 1996, 68, 2885-2889.

[27] Frens, G., Nature 1973, 241, 20-22.

[28] Mayer, A. B. R., Polym. Adv. Technol. 2001, 12, 96-106.

[29] Lafuma, F., Wong, K., Cabane, B., J. Colloid Interface Sci. 1991, 143, 9-21.

[30] Kang, S. H., Shortreed, M. R., Yeung, E. S., Anal. Chem. 2001, 73, 1091-1099.

[31] Mitnik, L., Heller, C., Prost, J., Viovy, J.-L., Science 1995, 267, 219-222.

[32] Magnúsdóttir, S., Isambert, H., Heller, C., Viovy, J.-L., Biopolymers 1999, 49, 385-401.

[33] Heller, C., Pakleza, C., Viovy, J.-L., Electrophoresis 1995, 16, 1423-1428.

[34] Song, L., Maestre, M. F., J. Biomol. Struct. Dynam. 1991, 9, 525-535.

[35] Iki, N., Kim, Y., Yeung, E. S., Anal. Chem. 1996, 68, 43214325.

[36] Zheng, J., Yeung, E. S., Anal. Chem. 2002, 74, 4536-4547.

[37] Zheng, J., Yeung, E. S., Anal. Chem. 2003, 75, 3675-3680.

[38] Bakajin, O. B., Duke, T. A., Chou, C. F., Chan, S. S., Austin, R. H., Cox, E. C., Phys. Rev. Lett. 1998, 80, 2737-2740.

[39] Olson, D. J., Johnson, J. M., Patel, P. D., Shaqfeh, E. S. G., Boxer, S. G., Fuller, G. G., Langmuir 2001, 17, 7396-7401. 